\title{
Basic Psychological Needs in Predicting Exercise Participation
}

\author{
Jennifer V. Martinez ${ }^{1}$, Crystal D. Oberle ${ }^{1 *}$, Alexander J. Nagurney ${ }^{2}$ \\ ${ }^{1}$ Department of Psychology, Texas State University, San Marcos, USA \\ ${ }^{2}$ Department of Psychology, University of Hawaii, Hilo, USA \\ Email: "oberle@txstate.edu
}

Received October 24 $4^{\text {th }}, 2012$; revised November $28^{\text {th }}, 2012$; accepted December $8^{\text {th }}, 2012$

\begin{abstract}
This study examined propositions stemming from self-determination theory (Deci \& Ryan, 1985), which contends that motivational consequences and positive outcomes are predicted by the needs for competence, relatedness, and autonomy. Participants completed the Psychological Need Satisfaction in Exercise (Wilson, Rogers, Rodgers, \& Wild, 2006) scale and had their gym access activity monitored for six weeks. Regression analyses revealed that only competence emerged as a statistically significant predictor of exercise participation, and that this prediction was true for women only $(p=.04)$. These findings suggest that exercise and health professionals must take care to ensure that this need is met, particularly in their female clients who may be impacted by traditional gender roles in sport contexts.
\end{abstract}

Keywords: Self-Determination Theory; Psychological Need Satisfaction; Exercise Participation; Gender

\section{Introduction}

The association between exercise and improved physical and mental health has been well documented (Biddle \& Mutrie, 2001). Exercise is important in preventing many diseases and medical conditions such as coronary heart disease, certain cancers, hypertension, obesity, diabetes, and osteoporosis (US Department of Health and Human Services, 2002). Despite the positive health benefits of exercise, physical inactivity is a common occurrence in industrialized countries. In 2009, the National Center for Health Statistics found that when considering all leisure-time physical activity, $33 \%$ of adults were considered inactive and only $35 \%$ engaged in such activity on a regular basis. Regarding vigorous leisure-time physical activity, $55 \%$ of adults never engaged in any periods of vigorous leisuretime physical activity lasting 10 minutes or more per week, and only $28 \%$ engaged in such activity three or more times per week. Furthermore, research has shown that whereas most individuals find it easy to begin an exercise program, about $50 \%$ tend to drop out within the first six months (Sallis \& Hovell, 1990).

This decline in exercise and decreased health corresponds to an epidemic rise in obesity rates (Guh et al., 2009). For example, based on their body mass index, $35 \%$ of adults are considered obese (National Center for Health Statistics, 2009). If the current trends in obesity continue, by 2015, 2 in every 5 adults will be obese (Kumanyika et al., 2008). Thus, the prominent rise in obesity and its related risk factors lead health and wellness professionals to investigate the factors that promote longterm engagement in exercise.

Lack of adherence to an exercise program may arise from a variety of biological, social, and psychological factors, as indicated in the literature review that is presented below. Central to behavioral choice and decision making in this context is motivation. While the complex and dynamic nature of influences on exercise participation make it difficult to single out a particular theory, perspective, or approach to understanding exercise be-

\footnotetext{
*Corresponding author.
}

havior, most theories on exercise behavior factor in motivation as an important contributing factor in determining exercise behavior (Biddle \& Mutrie, 2001).

\section{Self-Determination Theory}

Of the different motivation theories, self-determination theory (SDT; Deci \& Ryan, 1985) holds particular promise in predicting motivational factors, as well as psychological and emotional benefits in the exercise domain. SDT is a meta-theory comprised of many sub-theories that explain human motivation and development. One of the most important sub-theories is the basic psychological needs theory, which proposes that people have innate psychological needs that, when fulfilled, have positive influences on personal growth, psychosocial adjustment, and eudaimonic well-being. SDT assumes that a strong sense of competence, relatedness, and autonomy make up the basic needs and constitute the essential input that nurtures motivation and wellbeing across a variety of situations and cultures. The need for autonomy reflects the desire to organize experiences and behavior that is congruent with the integrated self. The need for competence reflects the desire to have an effect on the environment and attain valued outcomes. Last, the need for relatedness reflects the desire to feel connected and understood by others. Furthermore, SDT assumes that we are more motivated by situations where there is some choice, control, and self-determination. Conversely, we prefer not to be controlled by any external force. Thus, these constructs are what provide the foundation and are central to intrinsic motivation (Biddle \& Mutrie, 2001).

If the needs of autonomy, relatedness, and competence are satisfied, autonomous internal forms of motivation will encourage behavior. However, if the needs are thwarted, then this will lead to more controlling external forms of motivational regulation or motivation. Furthermore, Deci and Ryan (1985) state that it is within the social context that needs can be promoted or thwarted. According to SDT, the satisfaction of the basic psychological needs is fundamental to incorporating cultural norms and values into a coherent self-structure. The needs 
are considered to be innate and universal in their positive influence on well-being, while need-thwarting events can diminish energy.

SDT is among many other psychological theories which center importance on feelings of competence or efficacy for motivated behavior. It is believed that in order for individuals to carry out a behavior, they must first experience some level of effectiveness. According to Ryan, Williams, Patrick, and Deci (2009), this sense of competence is not only related to the individual's history and beliefs in capabilities, but also aspects of the social environment. However, unlike other theories, SDT is unique in emphasizing the importance of autonomy. Again, the capacity to act autonomously is strongly influenced by the social environment, which can vary from controlling to supportive. The concept of relatedness according to SDT applies more generally to contexts where individuals are surrounded by warmth, care, and involvement.

\section{Self-Determination Theory in Exercise}

Because exercise often requires attributions related to motivation such as persistence, time management, and self-regulatory skills, SDT is a relevant theory to study in the exercise context. In the view of SDT, exercise can be an inherently rewarding activity that contributes to positive outcomes such as happiness, subjective vitality, and persistence (Ryan, Fredrick, Lepes, Rubio, \& Sheldon, 1997). Areas of research on the tenets of SDT in the exercise domain have generally drawn the same conclusions. With children, autonomous self-regulation is positively related to both amount of physical activity (Vierling, Standage, \& Treasure, 2007) and intention to exercise (Biddle, Soos, \& Chatzisarantis, 1999). With regular recreational exercisers, higher levels of autonomous self-regulation lead to fewer exercise relapses and greater intentions to exercise (Thogersen-Ntoumani \& Ntoumanis, 2006), as well as greater exercise intensity (Standage, Sebire, \& Loney, 2008). With athletes, autonomy-supportive coaching produces more autonomous forms of motivation, which are predictive of persistence with the sport over time (Pelletier, Fortier Vallerand, \& Briere, 2001). Finally, in a metaanalysis of the self- determination continuum, researchers found moderately strong correlations between more self-determined forms of motivation and measures of intention and competence (Chatzisarantis, Hagger, Biddle, Smith, \& Wang, 2003).

Although there is support for SDT as a whole, support for the basic psychological needs theory within SDT research in the exercise domain is just beginning to emerge (Hagger \& Chatzisarantis, 2007). Nevertheless, a wide variety of literature implicates the needs of autonomy, competence, and relatedness as being essential to facilitating and sustaining motivation and well-being. For example, Gagne, Ryan, and Bargmann (2003) studied gymnasts' experiences of motivation and well-being at each practice over a four-week period. Results from the study indicated that athletes with more autonomous forms of motivation had more positive experiences in the sport and were higher in well-being. Furthermore, the changes from pre to post practice well-being were related to basic need satisfaction. That is, gymnasts who had perceptions of support for relatedness, autonomy, and competence displayed more positive affect, more vitality, higher state self-esteem, and less negative affect. In a similar study with over 500 adult sport participants, Adie, Duda, and Ntoumanis (2008) found that coach autonomy support predicted satisfaction of all three basic needs. Also, basic need satisfaction predicted greater subjective vitality when engaged in sports. Those with low levels of autonomy were more likely to feel emotionally and physically drained by engagement in sport. Moreover, Kowal and Fortier (2000) found that athletes who were high in relatedness, autonomy, and competence showed more positive affect, more vitality, higher state selfesteem, and less negative affect. Again, in another group of young athletes, satisfaction of each of the three needs was correlated negatively to athlete burnout (Perreault, Gaudreau, Lapointe, \& LaCroix, 2009). The needs of competence, relatedness, and autonomy have also been shown to contribute to enhanced feelings of positive well-being and positive affect, as well as reduced experiences of psychological distress and negative affect during exercise participation (Wilson, Mack, Blanchard, \& Gray, 2009) and enhanced subjective vitality among exercisers (Wilson \& Rogers, 2008).

Because both positive affect and confidence in one's ability to be physically active are related to greater participation in exercise (Frederick \& Ryan, 1993; Sallis et al., 1989), it is expected that the satisfaction of the basic psychological needs would relate to exercise participation. Indeed, Ryan et al. (1997) found that enjoyment and competence motives were associated with greater participation in exercise programs; however, the basic psychological needs were not assessed. Nevertheless, research suggests that need support and satisfaction could contribute to exercise persistence over time. For example, Wilson, Rodgers, and Fraser (2002) surveyed a sample of 500 university students and staff enrolled in an exercise class and found that psychological need satisfaction was positively correlated with intrinsic motivation and autonomous regulations. In turn, these forms of motivation were positively associated with self-reported exercise behavior. Likewise, Edmunds, Ntoumanis, and Duda (2006) found in a large sample of regular exercisers aged 16 to 64 that competence needs satisfaction and autonomous regulation positively predicted degree of strenuous exercise.

The impact of the basic psychological needs on exercise behavior has also been demonstrated through experimental manipulation. For example, Vansteenkiste, Simon, Lens, Sheldon, and Deci (2004) examined the impact of need satisfaction on high school students' exercise engagement in physical education. In the study, exercises were presented in a need supportive or controlling way. This was accomplished by giving students the option to participate in exercises or forcing them to engage in the activity. Results indicated that, compared to the controlling context, participants in the need supportive condition displayed greater effort and were more likely to persist and receive higher performance scores from teachers. Likewise, Edmunds, Ntoumanis, and Duda (2008) examined the impact of need supportive teaching styles on psychological need satisfaction and exercise behavior. Female group fitness class participants in a 10-week exercise class were assigned to an SDT-based or typical teaching style. In the SDT-based class, the instructor provided need support by taking the perspective of the exercisers into account, acknowledging their feelings, and providing rationale for exercise. Compared to the control group, participants in the SDT condition displayed a significantly greater linear increase in relatedness and competence need satisfaction. Participants in the SDT condition also attended class significantly more often.

Despite the importance of psychological needs to SDT's framework, a majority of the research utilizing the theory in the exercise domain has focused on the relationship between be- 
havioral regulations with behavior. Although there is a good amount of evidence linking enhanced feelings of competence with more self-determined forms of regulation, there is less data on the theory's claims regarding autonomy and relatedness (Wilson \& Rogers, 2008). In fact, many findings on the relationship between satisfying basic psychological needs within the exercise contexts have produced mixed findings.

For example, cross-sectional studies of exercisers indicate that perceived competence more than autonomy or relatedness displays the strongest associations for more self-determined motivations which, in turn, should predict vitality, well-being, and persistence. Yet, longitudinal studies indicate that psychological need fulfillment varies across time where autonomy and competence both play a role in developing self-determined regulation. Furthermore, among the three needs, the role of perceived relatedness is less understood. For example, Wilson and Rodgers (2003) reported no statistically significant correlation between perceived relatedness and behavioral regulation, and Edmunds et al. (2006) also showed that perceived relatedness did not predict intrinsic motivation. While Wilson and Rogers (2008) showed a relationship between need satisfaction and self-determination motivations, their research did not explore the behavioral outcomes of such findings. Vlachopoulous and Michailidou (2006) did investigate satisfaction of needs with exercise frequency and found that competence appeared a stronger indicator of exercise frequency than autonomy and relatedness. However, the sample of the study was Greek-speaking exercisers, limiting the generalizability of the study to other cultures and contexts.

\section{Purpose of the Study}

The current study tests the tenets of psychological needs satisfaction, as a component of SDT, in the exercise domain. Although there is increased attention in the role of basic psychological needs in determining exercise behavior, much of the research has focused on instrument development issues or has focused on the relationship between fulfillment of the basic psychological needs and self regulations. Furthermore, although past research has examined the model of the basic psychological needs within the exercise setting, activity levels were assessed by self-report measures that may be subject to participation biases (Wilson, Mack, Gunnell, Oster, \& Gregson, 2008). In addition, many of the past studies were conducted in countries outside of the United States, calling into question the generalizability of SDT in predicting exercise behaviors (Vlachopoulos \& Michailidou, 2006). More research is needed on SDT in a variety of populations with different measures of exercise behavior.

The current study attempts to fill in the gaps within the literature and investigate the three constructs of basic needs under SDT (i.e., competence, relatedness, and autonomy) and their ability to predict participation in exercise. Additionally, the study is one of the first to explore whether gender moderates these predictive relationships.

\section{Method}

\section{Participants}

The sample was comprised of students at Texas State University with access to the campus recreation center. Participation was voluntary and open to all students who reported using the campus recreation facilities. Data were gathered from 101 students for the study. Of these students, 65 men and 36 women comprised the sample, ranging in age from 18 to 33 years $(M=$ $21.90, S D=3.11)$. Within the sample, $65.3 \%$ were Caucasian, $21.8 \%$ were Hispanic, $5.9 \%$ were bi- or multi-racial, $4.0 \%$ were Asian or Pacific Islander, $2.0 \%$ were African American, and $1.0 \%$ were Native American or Alaskan Native.

\section{Materials and Procedure}

Data for the study were collected at the Texas State University recreation center. Participants were randomly approached as they entered the recreation center, or they were invited to participate at the end of group exercise classes in cycle, cardio, and strength formats. Upon consent, participants completed the Psychological Need Satisfaction in Exercise (PNSE; Wilson et al., 2006), an 18-item self-report measure of psychological need satisfaction experience in exercise contexts. The PNSE contains three subscales, each comprising items designed to reflect respondents' perceptions of competence, autonomy, and relatedness felt during a typical exercise session. Participants responded to each item on a 7 -point Likert scale $(1=$ not at all true... 7 = very true) in terms of how they feel while exercising. Note that this scale differs from the original 6-point scale $(1=$ false, $6=$ true). This change was made to include a standard middle-point option and to provide labels that correspond to each number. Wilson et al. (2006) provided initial evidence that supported the structural and convergent validity of PNSE scores in physically active young adult exercisers and reported that the internal consistency for the PNSE subscales of competence, autonomy, and relatedness were $.90, .90$, and .91 , respectively.

Exercise behavior was recorded via the recreation center's electronic entry. Turnstiles located at the front of the recreation center allow admission via the student's unique student ID number, handprint, or ID card. For each student, an electronic $\log$ records the number of entries and location of entry into the recreation center. Thus, participants' number of entries into the recreation center was uploaded from the main database for a total count of exercise participation over a six-week period following their survey completion.

\section{Results}

The first inferential analysis was a multiple regression to provide an answer to the first set of research questions regarding whether autonomy, competence, and relatedness predict exercise participation. This analysis had entries for autonomy, competence, and relatedness scores as independent variables in order to predict total number of times the participant accessed the recreation center over 6 weeks. Only competence significantly contributed to the prediction of student recreation center access (see Table 1).

Table 1.

Regression analysis for needs predicting exercise participation.

\begin{tabular}{ccccc}
\hline Variable & $B$ & $\beta$ & $t$ & $p$ \\
\hline Competence & .630 & .228 & 1.991 & $.049^{*}$ \\
Autonomy & .339 & .116 & 1.045 & .299 \\
Relatedness & .018 & .210 & .009 & .932 \\
\hline
\end{tabular}

Note: ${ }^{*} p<.05$. 
The next three inferential analyses were stepwise regression analyses to provide answers to the second set of research questions regarding whether gender moderates the relationships between the psychological needs and exercise participation. For each of these three analyses (one for each of the psychological needs), sex and the centered needs variable were entered in the first step, and the interaction between these two variables was entered in the second step. As with the first regression analysis, the criterion variable was the total number of times the participant accessed the recreation center over 6 weeks. The analyses revealed no significant interaction between autonomy and gender, or between relatedness and gender, in the prediction of exercise participation (see Table 2). Using a standard alpha level of .05 , the interaction between competence and gender would also be considered statistically non-significant. However, given that gender differences have never previously been studied in this domain, a more liberal criterion of .10 was used to determine whether post-hoc tests should be performed. Thus, two linear regression analyses were conducted: one for males and one for females. Results indicated that for men, competence was not a significant predictor of exercise participation $(\beta$ $=.111, p=.379)$. Yet, for women, competence was a significant predictor of exercise $(\beta=.342, p=.041)$.

\section{Discussion}

The present study was guided by two research questions. The first question focused on whether competence, autonomy, and relatedness predicted exercise participation as defined by the number of times that participants scanned their student ID's to gain access into the student recreation center. Analyses related to the first question revealed that of the three basic psychological needs, only competence was a significant predictor of exercise participation. The second question examined whether gender moderated the relationship between competence, autonomy, and relatedness and exercise participation. For this second

Table 2.

Regression analyses for interaction between needs and gender.

\begin{tabular}{|c|c|c|c|c|}
\hline Variable & $B$ & $\beta$ & $t$ & $p$ \\
\hline \multicolumn{5}{|l|}{ Step 1} \\
\hline Autonomy (centered) & .471 & .161 & 1.570 & .120 \\
\hline Gender & 6.257 & .198 & 1.934 & .056 \\
\hline \multicolumn{5}{|l|}{ Step 2} \\
\hline Autonomy $\times$ Gender & .945 & .167 & 1.367 & .932 \\
\hline \multicolumn{5}{|l|}{ Step 1} \\
\hline Relatedness (centered) & .471 & .084 & .865 & .389 \\
\hline Gender & 7.963 & .252 & 2.588 & $.011^{*}$ \\
\hline \multicolumn{5}{|l|}{ Step 2} \\
\hline Relatedness $\times$ Gender & -.188 & -.068 & -.457 & .649 \\
\hline \multicolumn{5}{|l|}{ Step 1} \\
\hline Competence (centered) & .643 & .233 & 2.339 & $.021^{*}$ \\
\hline Gender & 5.794 & .183 & 1.843 & .068 \\
\hline \multicolumn{5}{|l|}{ Step 2} \\
\hline Competence $\times$ Gender & 1.027 & .238 & 1.860 & .066 \\
\hline
\end{tabular}

question, gender did moderate the relationship between competence and exercise participation. Results revealed that competence predicted exercise participation in women, but not in men. However, gender did not moderate the relationship between relatedness or autonomy and exercise participation.

According to the results of this study, only competence emerged as a significant predictor of exercise participation. This finding is not surprising, considering that in past research, competence accounted for the greatest portion of exercise behavior variance among the three needs (Wilson, Mack, Gunnell, Oster, \& Gregson, 2008). Furthermore, in support of SDT, Edmunds, Ntoumanis, and Duda (2007) found that competence need satisfaction partially mediated the relationship between perceived autonomy support from exercise instructors and intrinsic motivation. In addition, the same researchers tested SDT using a hierarchical regression to examine the importance of motivation-related variables in self-reported exercise behavior and found that competence need satisfaction and autonomous forms of regulation (i.e., identified and introjected regulations) positively predicted strenuous exercise behavior. According to researchers, competence need satisfaction had a direct and indirect (i.e., identified regulation) effect on behavioral investment.

Thus, it is suggested that feelings of competence result in increased exercise behavior by reinforcing the personal importance of exercise. Given that exercise uses the physical systems of the body, it is not surprising that competence emerges as a predictor of exercise participation, compared to autonomy and relatedness which are not as physical in concept. Perceptions of competence and ability are often found to influence physical activity. Research often shows that physically active people report higher levels of perceived competence, suggesting that individuals seek domains where ability can be demonstrated and incompetence can be avoided (Biddle \& Mutrie, 2001). Furthermore, research using other constructs related to competence, such as self-efficacy, support a strong relationship between elevated levels of perceived competence and physical activity in people of all ages (Crocker, Eklund, \& Kowalski, 2000; Hayes, Crocker, \& Kowalski, 1999).

What is interesting is the finding that competence predicted exercise participation in women, but not in men. According to SDT, the innate needs are universal to all cultures, across gender and the lifespan. Indeed, Standage, Duda, and Pensgaard (2005) tested the invariance of the SDT framework across gender and found the tenets of SDT to be invariant across men and women. Similarly, Vlachopoulos and Karavani (2009) found equivalence of the effects of the psychological needs for autonomy, competence, and relatedness on subjective vitality across gender. However, neither study investigated exercise participation as the outcome. Rather, both studies focused on the SDT tenet that the basic psychological needs promote wellbeing.

No studies to date have explored the moderating role of gender on exercise participation in conjunction with basic psychological needs. In the current study, the fact that competence predicted exercise participation in women but not in men could be due to gender roles. It is possible that in the exercise domain, physical activities and the physical self are inherently "male" (Hagger, Biddle, \& Wang, 2005). Thus, women may feel intimidated when in the exercise context and therefore a degree of competence would be needed. Examples of the gender differences in regards to exercise participation have indeed been noted and regarded as one of the most consistent findings in the 
literature (Biddle \& Mutrie, 2001). In a population study of motives for participation in exercise, women were more likely to report emotional barriers to exercise. Specifically, personal beliefs that they are not "sporty" were considered strong barriers to physical activity (Allied Dunbar National Fitness Survey, 1992). However, it has also been shown that when the expenditure of exercise is seen as a barrier to participation, participants were more likely to take on leisurely activities such as walking (Salmon et al., 2003). Thus, participation in activity may be influenced by the type of activity, whereby exercise that does not clearly display "sport" competence may be more easily taken by women (i.e. group exercise, yoga, etc.). Yet, the converse may be true for men whereby competence is needed for participation in predominately female activities.

In a study that tested the assumption of universality of the psychological needs across gender in secondary school students, boys tended to score higher in perceived positive feedback, perceived competence, perceived interest, and perceived effort in physical education (Koka \& Hein, 2005). These findings suggest that boys were able to demonstrate more competence in the physical context and that they were more likely to receive positive feedback than girls. Thus, such perceptions are likely to lead to girls perceiving physical settings as more controlling because it is not an area where they feel capable of demonstrating competence (Koka \& Hein, 2005). Since these studies were conducted on young children, it is possible that in young adults competence must be perceived in women in order for them to continue in physical activity, whereas men do not require this need.

Other research supports the role of competence in women. For example, in Estonian youth, it was found that body-related perception of competence was the dominant predictor of activity in young women (Raudsepp, Viira, \& Liblik, 2004). However, Kowalski, Crocker, and Kowalski (2001) found that the role of competence in predicting exercise behavior is not affected by self-presentational concerns or physique in women. Nevertheless, this finding contradicts the universality proposition set forth by SDT. Few researchers have explored the basic psychological needs and exercise participation across gender. Although competence clearly has a significant role in predicting exercise behavior, possible reasons for the gender differences will need further investigation.

\section{Implications for Further Research}

Given the study's findings, there are discrepancies in SDT concerning the universal nature of the basic psychological needs. SDT in the physical activity and exercise context is still flourishing. Little research has been done exploring the relationship between the basic psychological needs and objective forms of exercise behavior, especially across genders. Because competence is an important factor in exercise participation in women, researchers should examine the influence of gender roles or body-related motives. In addition, future work would benefit by examining the specific type of exercise mode and intensity. It may be that different types of exercise (e.g., weight training, cardiovascular activities, and sports) may require different need satisfaction. For example, those engaging in exercise for sport may require more competence than those engaging in cardiovascular activities which require less skill. Given that this study was cross-sectional, future research should conduct field experiments manipulating competence to determine if similar re- sults are obtained. That is, experimental designs should be utilized to determine the casual attributions implied in SDT between the basic psychological needs and positive outcomes.

Vallerand (2001) noted that research typically considers the effects of satisfying competence, but has been slow to consider autonomy and relatedness. Thus, although the current study adds to the current literature, future work is needed to examine the constructs of relatedness and autonomy. In addition, there may be measurement issues that need to be addressed in the research on SDT and the individual in the exercise context. While the evidence is favorable to the construct validity of scores from the PNSE, it has been argued that future research should focus on construct validation of the basic psychological needs. Further, it has been reported that criterion validity coefficients from structural equation modeling analyses with perceived relatedness are incongruent with SDT. That is, there poses no evidence for changes in perceived relatedness in affect or well-being which are two of the central outcomes dictated by SDT (Wilson et al., 2008).

Also, it should be noted that the sample used in this study was university students with access to a recreation center. University students have additional burdens that are not typical in the population such as exams and extra-curricular activities. Thus, this may have influenced participation in exercise. Other issues stem from the fact that this population is generally young and healthy; future research would benefit from examining the basic psychological needs in the exercise context among older adults. Finally, participants in the study were followed prospectively for six weeks; future research should take a longitudinal assessment of exercise participation as participants may dropout of their exercise routine over time.

\section{Implications for Practice}

Based on the positive physical and psychological health benefits from regular exercise, and the small number actively engaged in exercise, research is needed to investigate factors associated with exercise persistence. Although SDT does not take into account the wide variety of factors that relate to exercise participation, the theory is attractive to health professionals because it offers a parsimonious account for behavior. Past research and the current study suggest that competence is a particularly relevant need in the exercise domain, and that exercise instructors and professionals in the health field should take special care that this need is met. For example, Edmund, Ntoumanis, and Duda (2005) manipulated an exercise instructor's teaching style to be controlling or autonomy-supportive for a group of exercisers and found that exercisers with the supportive instructor had an increase in competence, class enjoyment, and positive affect over time. Thus, by following the tenets outlined in SDT, exercise and health professionals can develop interventions that can increase competence and other positive outcomes.

Overall, research findings suggest that, in terms of exercise participation, health and exercise professionals should make sure that the basic psychological needs of individuals engaging in an exercise regimen are met. Of these needs, studies have indicated that competence need satisfaction is particularly important in predicting exercise behavior. This can be achieved by designing structured programs that allow for gradual and observable improvement, setting up achievable goals, and providing positive feedback. 
On the basis of this and past research on SDT in the exercise setting, it seems that exercise professionals should provide a structure that sets realistic goals that are made clear to the individual, and that praise is given for effort made to achieve that goal (Edmund et al., 2009). In particular, the need for competence may be especially important to recognize in women. Thus, women who may feel intimated by exercise programs because of gender roles will need additional support and guidance in an exercise program.

\section{Implications for Theory}

According to the theory, fulfillment of these basic psychological needs represents innate requirements of the self that aid in the internalization of ambient values and help to integrate the self within and with the social environment. Thus, fulfillment of these needs promotes well-being and positive forms of motivation for health behaviors such as exercise (Wilson et al., 2008). Social environments that fail to satisfy the innate psychological needs lead to alienation and impede human development (Deci \& Ryan, 2002). In the current study, competence, relatedness, and autonomy were examined individually for their predictive utility in exercise behavior. However, in SDT, the basic psychological needs must be complementary. That is, all three needs must be met so as to allow for growth and integrity (Ryan \& Deci, 2000).

Yet, SDT has received criticism regarding the compatibility of autonomy and relatedness. It has been stated that the manner in which needs satisfaction unfolds in not exclusionary. Rather, SDT proposes the idea of complementarity in satisfaction of the psychological needs such that the satisfaction of autonomous needs can occur only in light of satisfaction for competence and relatedness (Deci \& Ryan, 2002). Support for this comes from Hagger, Chatizisarantis, and Harris (2006), who found that latent variables for the basic psychological needs could be explained by a single global factor.

Other research has shown that the needs for competence and autonomy are positively related while less strong relationships exist between these constructs and relatedness. For example, Wilson et al. (2002) showed in a sample of exercise class attendees that there was a moderate relationship between competence and autonomy and a weaker relationship between these needs and relatedness. In a similar study of fitness class attendees, there was a greater satisfaction of competence and autonomy than relatedness needs (Wilson \& Rodgers, 2003). Again, in the current study, competence was found to be main predictor of exercise participation while the other constructs did not, further testing the notion of complementarity.

There have also been mixed findings regarding the basic psychological needs in the exercise setting. In five studies that looked at exercise-specific feelings of competence, autonomy, and relatedness over one and six months, results suggested that there were fluctuations in psychological need fulfillment over time with a trend towards increased perceptions of each need from baseline as a result of an exercise program (Wilson et al., 2008). Yet, in two of the studies, there were the greatest increases in perceived relatedness over the course of 12-week exercise programs.

Finally, as mentioned previously, the results from this study contradict the theory's tenet that the basic psychological needs are universal across gender. Although past research has demonstrated universality, the fact that the current study did not could be due to the outcome variables used. Many studies examined well-being, but did not examine exercise participation (Standage et al., 2005; Vlachopoulos \& Karavani, 2009). Also, it is important to note that this study did not examine the full framework proposed by Deci and Ryan (1985), in which the basic psychological needs moderate autonomous forms of regulations which predict behavior. Thus, before interpretations with theory are made, more research will be needed.

\section{Limitations}

While the findings discussed thus far add to the sparse research on the basic psychological needs in exercise, several limitations should be acknowledged. First, the current study was non-experimental in design. Furthermore, this study used a convenience sample of university students who have access to a recreation center as part of their university fees and therefore may not accurately represent the average population. Thus, the findings must be interpreted with caution when making casual references. Second, the criterion in this study was restricted to exercise participation at a recreation center at the expense of other physical activity settings. Although this study was one of the few studies to use objective measures of exercise participation, exercise participation was measured using number of times the participant accessed the recreation center using their ID, which may be misleading because there was no recording of the types of activities individuals were engaging in, some of which may have been non-physical in nature (e.g., studying).

One major advantage of using the recreation center's access database for measuring exercise behavior is that it is observable, whereas much of the past research on self-determination in the exercise domain has used self-report as a means to measure activity. Yet, a disadvantage to the approach used in this study is that although exercise activity is recorded in an observable manner, the duration and types of activities the individual chooses to engage in remain unknown. In addition, outside gym memberships and other leisure time physical activity were not measured.

\section{Summary and Conclusion}

In summary, the purpose of this study was to examine the basic psychological needs sub-theory of SDT in the exercise setting. The observations from this study suggest that competence is particularly important in predicting exercise behavior. While the evidence of the basic psychological needs is scarce compared to research on the behavioral regulations, the available research suggests that perceptions of competence, autonomy, and relatedness form inputs into well-being and behavior. Nevertheless, findings from this study and the theoretical propositions set forth by Deci and Ryan (2002) suggest that the basic psychological needs may be a promising avenue for researchers and exercise professionals. The present research shows that competence is an important factor in exercise participation. Furthermore, it is interesting to note that this relationship is more salient among women. Gender roles may likely be at play, but future research will be needed to elucidate this study's findings in regards to SDT and applications.

\section{REFERENCES}

Adie, J., Duda, J., \& Ntoumanis, N. (2008). Autonomy support, basic 
need satisfaction and the optimal functioning of adult male and female sport participants: A test of basic needs theory. Motivation and Emotion, 4, 189-199. doi:10.1007/s11031-008-9095-z

Allied Dunbar National Fitness Survey (1992). Summary report. Activity and health research. London: Sports Council and Health Education Authority.

Biddle, J. H., \& Mutrie, N. (2001). Psychology of physical activity: Determinants, well-being and interventions. London: Routledge.

Biddle, S. J. H., Soos, I., \& Chatzisarantis, N. L. (1999). Predicting physical activity intentions using goal perspectives and self-determination theory approaches. European Psychologist, 4, 83-89.

Chatzisarantis, N., Hagger, M. S., Biddle, S., Smith, B., \& Wang, J. (2003). A meta-analysis of perceived locus of causality in exercise, sport, and physical education contexts. Journal of Sport and Exercise Psychology, 25, 284-306.

Crocker, P. R., Eklund, R. C., \& Kowalski, K. C. (2000). Children's physical activity and physical self-perceptions. Journal of Sport Sciences, 18, 383-394. doi:10.1080/02640410050074313

Deci, E. L., \& Ryan, R. M. (1985). Intrinsic motivation and self-determination in human behavior. New York: Plenum Press.

Deci, E. L., \& Ryan, R. M. (2002). Handbook of self-determination research. Rochester: University of Rochester Press.

Edmunds, J. K., Ntoumanis, N., \& Duda, J. L. (2006). A test of selfdetermination theory in the exercise domain. Journal of Applied Social Psychology, 36, 2240-2265.

doi:10.1111/j.0021-9029.2006.00102.x

Edmunds, J. K., Ntoumanis, N., \& Duda, J. L. (2007). Perceived autonomy support and psychological need satisfaction as key psychological constructs in the exercise domain. In M. Hagger, \& N. L. D. Chatzisarantis (Eds.), Self-determination in exercise and sport (pp. 35-51). Champaign, IL: Human Kinetics.

Edmunds, J. K., Ntoumanis, N., \& Duda, J. L. (2008). Testing a self-determination theory based teaching style in the exercise domain. European Journal of Social Psychology, 38, 375-388. doi: $10.1002 /$ ejsp.463

Frederick, C. M., \& Ryan, R. M. (1993). Differences in motivation for sport and exercise and their relationships with participation and mental health. Journal of Sport Behavior, 16, 125-145.

Gagne, M., Ryan, R. M., \& Bargmann, K. (2003). The effects of parent and coach autonomy support on need satisfaction and well-being of gymnasts. Journal of Applied Sport Psychology, 15, 372-390. doi:10.1080/714044203

Guh, D. P., Zhang, W., Bansback, N., Amarsi, Z., Birmingham, C. L., \& Anis, A. H. (2009). The incidence of co-morbidities related to obesity and overweight: A systematic review and meta-analysis. BMC Public Health, 9, 88. doi:10.1186/1471-2458-9-88

Hagger, M. S., Biddle, S. J. H., \& Wang, C. K. (2005). Physical selfconcept in adolescence: Generalizability of a multidimensional, hierarchical model across gender and grade. Educational and Psychological Measurement, 65, 297-322. doi:10.1177/0013164404272484

Hagger, M. S., \& Chatzisarantis, N. L. (2007). Intrinsic motivation and self-determination in exercise and sport. Champaigne, IL: Human Kinetics.

Hagger, M. S., Chatzisarantis, N. L. D., \& Harris, J. (2006). From psychological need satisfaction to intentional behavior: Testing a motivational sequence in two behavioral contexts. Personality and Social Psychology Bulletin, 32, 131-138. doi:10.1177/0146167205279905

Hayes, S. D., Crocker, P. R. E., \& Kowalski, K. C. (1999). Gender differences in physical self-perception, global self esteem and physical activity: Evaluation of the physical self-perception profile model. Journal of Sport Behavior, 22, 1-14.

Koka, A., \& Hein, V. (2005). The effect of perceived teacher feedback on intrinsic motivation in physical education. International Journal of Sport Psychology, 36, 91-106.

Kowal, J., \& Fortier, M. S. (2000). Testing relationships from the hierarchical model of intrinsic and extrinsic motivation using flow as a motivational consequence. Research Quarterly for Exercise and Sport, 71, 171-181.

Kowalski, N. P., Crocker, P., \& Kowalski, K. C. (2001). Physical self and physical activity relationships in college women: Does social physique anxiety moderate effects? Research Quarterly for Exercise and Sport, 72, 55-62.

Kumanyika, S. K., Obarzanek, E., Stettler, N., Bell, R., Field, A. E., Fortmann, S. P., \& Hong, Y. (2008). Population-based prevention of obesity: The need for comprehensive promotion of healthful eating, physical activity, and energy balance. Circulation, 118, 428-464. doi:10.1161/CIRCULATIONAHA.108.189702

National Center for Health Statistics (2009). Summary health statistics for US adults: National health interview survey. http://www.cdc.gov/nchs/fastats/exercise.html

Pelletier, L. G., Fortier, M. S., Vallerand, R. J., \& Brière, N. M. (2001). Associations among perceived autonomy support, forms of self-regulation, and persistence: A prospective study. Motivation and Emotion, 25, 279-306. doi:10.1023/A:1014805132406

Raudsepp, L., Viira, R., \& Liblik, R. (2004). Stability of physical selfperceptions of adolescents with different levels of physical activity. Journal of Human Movement Studies, 47, 143-153.

Ryan, R. M., \& Deci, E. L. (2000). The darker and bright sides of human existence: Basic psychological needs as a unifying concept. Psychological Inquiry, 11, 319-338. doi:10.1207/S15327965PLI1104_03

Ryan, R. M., Frederick, C. M., Lepes, D., Rubio, N., \& Sheldon, K. M. (1997). Intrinsic motivation and exercise adherence. International Journal of Sport Psychology, 28, 335-354.

Ryan, R. M., Williams, G. C., Patrick, H., \& Deci, E. L. (2009). Selfdetermination theory and physical activity: The dynamics of motivation in development and wellness. Hellenic Journal of Psychology, 6, 107-124.

Sallis, J. F., \& Hovell, M. (1990). Determinants of exercise behavior. Exercise and Sport Sciences Reviews, 18, 307-330. doi:10.1249/00003677-199001000-00014

Sallis, J. F., Hovell, M. F., Hofstetter, C. R., Faucher, P., Elder, J. P., Blanchard, J., et al. (1989). A multivariate study of determinants of vigorous exercise in a community sample. Preventive Medicine, 18, 20-34. doi:10.1016/0091-7435(89)90051-0

Salmon, J., Owen, N., Crawford, D., Bauman, A., \& Sallies, J. F. (2003). Physical activity and sedentary behavior: A population-based study of barriers, enjoyment, and preference. Health Psychology, 22, 178-188. doi:10.1037/0278-6133.22.2.178

Standage, M., Duda, J. L., \& Pensgaard, A. M. (2005). The effect of competitive outcome and task-involving, ego-involving, and cooperative structures on the psychological well-being of individuals engaged in a co-ordination task: A self-determination approach. Motivation and Emotion, 29, 41-68. doi:10.1007/s11031-005-4415-z

Standage, M., Sebire, S. J., \& Loney, T. (2008). Does exercise motivation predict engagement in objectively assessed bouts of moderate-intensity exercise behavior? A self-determination theory perspective. Journal of Sport and Exercise Psychology, 30, 337-352.

Thogersen-Ntoumani, C., \& Ntoumanis, N. (2006). The role of selfdetermined motivation in the understanding of exercise-related behaviours, cognitions and physical self-evaluations. Journal of Sports Sciences, 24, 393-404. doi:10.1080/02640410500131670

US Department of Health and Human Services (2002). Physical activity fundamental to preventing disease.

http://aspe.hhs.gov/health/reports/physicalactivity

Vallerand, R. J. (2001). A hierarchical model of intrinsic and extrinsic motivation in sport and exercise. In G. C. Roberts (Ed.), Advances in motivation in sport and exercise (pp. 263-319). Champaign, IL: Human Kinetics.

Vansteenkiste, M., Simons, J., Lens, W., Sheldon, K. M., \& Deci, E. L. (2004). Motivating persistence, deep level learning and achievement: The synergistic role of intrinsic-goal content autonomy-supportive context. Journal of Personality and Social Psychology, 87, 246-260. doi:10.1037/0022-3514.87.2.246

Vierling, K. K., Standage, M., \& Treasure, D. C. (2007). Predicting physical activity and attitudes toward physical activity in an "at-risk" youth sample: A test of self-determination theory. Psychology of Sport and Exercise, 8, 795-781. doi:10.1016/j.psychsport.2006.12.006

Vlachopoulos, S. P., \& Karavani, E. (2009). Psychological needs and subjective vitality in exercise: A cross-gender situational test of the needs universality hypothesis. Hellenic Journal of Psychology, 6, 
207-222.

Vlachopoulos, S. P., \& Michailidou, S. (2006). Development and initial validation of a measure of autonomy, competence, and relatedness in exercise: The Basic Psychological Needs in Exercise Scale. Measurement in Physical Education and Exercise Sciences, 10, 179-201. doi:10.1207/s15327841mpee1003_4

Wilson, P. M., Mack, D. E., Blanchard, C. M., \& Gray, C. E. (2009). The role of perceived psychological need satisfaction in exercise-related affect. Hellenic Journal of Psychology, 6, 183-206.

Wilson, P. M., Mack, D. E., Gunnell, K., Oster, K., \& Gregson, J. P. (2008). Analyzing the measurement of psychological need satisfaction in exercise contexts: Evidence, issues, and future directions. In M. P. Simmons (Ed.), Sport and exercise psychology research advances (pp. 361-391). Hauppauge: Nova Science Publishers.

Wilson, P. M., \& Rodgers, W. M. (2003). The relationship between psychological needs, self-determined motivation, exercise attitudes, and physical fitness. Journal of Applied Social Psychology, 33, 23732392. doi:10.1111/j.1559-1816.2003.tb01890.x

Wilson, P. M., Rodgers, W. M., \& Fraser, S. N. (2002). Examining the psychometric properties of the behavioral regulation in exercise questionnaire. Measurement in Physical Education and Exercise Science, 6, 1-21. doi:10.1207/S15327841MPEE0601_1

Wilson, P. M., \& Rogers, W. T. (2008). Examining relationships between perceived psychological need satisfaction and behavioural regulations in exercise. Journal of Applied Biobehavioral Research, 13, 119-142. doi:10.1111/j.1751-9861.2008.00031.x

Wilson, P. M., Rogers, W. T., Rodgers, W. M., \& Wild, T. C. (2006). The psychological need satisfaction in exercise scale. Journal of Sport and Exercise Psychology, 28, 231-251. 